\title{
Marine heat waves threaten kelp forests
}

Article in Science · February 2020

Dol: 10.1126/science.aba5244

\section{CITATIONS}

7 authors, including:

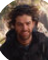

Nur Arafeh-Dalmau

The University of Queensland

16 PUBLICATIONS 39 CITATIONS

SEE PROFILE

Gabriela Montaño-Moctezuma

Autonomous University of Baja California

43 PUBLICATIONS 258 CITATIONS

SEE PROFILE

Some of the authors of this publication are also working on these related projects:

Project Sandy shore ecology View project

Project White Abalone Restoration View project
READS

524

David S Schoeman

University of the Sunshine Coast

163 PUBLICATIONS 7,393 CITATIONS

SEE PROFILE

1.7 Fiorenza Micheli

Stanford University

298 PUBLICATIONS 24,071 CITATIONS

SEE PROFILE 


\section{Marine heatwaves threaten kelp forests}

Marine kelp forests, among the most productive ecosystems on our planet (1), are in danger. The increase in the frequency and intensity of extreme climatic events (2) such as marine heatwaves is compromising kelp forests' capacity to produce goods and services (such as biomass of commercial fisheries, coastal protection, nutrient cycling, carbon sequestration, and recreational opportunities) that are worth billions of dollars to humanity (3). However, despite increasing climate-change advocacy and the overwhelming evidence demonstrating social and ecological impacts of climate change (4), political denial and inaction are jeopardizing society's ability to respond adequately to the multifaceted consequences of the accelerating pace of climate-driven loss of marine forests.

Between 2014 and 2016, extreme marine heatwaves of unprecedented duration and magnitude in the northwestern Pacific Ocean decimated giant kelp forest ecosystems across the U.S. state of California and Baja California, Mexico (5-7). Three years later, the onceextensive giant kelp forests have not recovered. Many of these underwater forests are now gone, replaced by smaller kelps or by sea urchin "barrens" (7), which can no longer provide food and shelter to diverse ecological communities. Meanwhile, at the UN climate conference COP25, the international community lost a valuable opportunity to tackle the climate crisis, mainly due to the lack of ambitious commitments by major players who are denying scientific evidence (8).

Kelp forests embody the concept of "sentinel systems" (early indicators) in the face of climate change. Their loss is an emergent global conservation issue (9) that signals future impacts throughout the marine realm. If political authorities fail to act and support climate-smart strategies (10), inaction will be followed by substantial economic losses. Alarmingly, $\mathrm{CO}_{2}$ emissions continue a trend of increase (11); unless this trend is reversed, studies predict a nearpermanent marine heatwave status by the end of the 21st century (12). Now is the time to act: We need international agreements to decrease future global $\mathrm{CO}_{2}$ emissions as well as government policies to mitigate existing local threats. Countries need to prioritize science-based mitigation and adaptation solutions, including improved management of anthropogenic impacts unrelated to climate change, the development of sea urchin markets and ranches, the exploration of climate-safe restoration sites, and the identification of genetically resilient kelp stocks. These changes will require investment in research and environmental protection. Increased human capacity will also be needed to halt and reverse the ongoing rapid loss of ecosystems and their services to people.

Nur Arafeh-Dalmau1,2*, David S. Schoeman ${ }^{3,4}$, Gabriela Montaño-Moctezuma ${ }^{5}$, Fiorenza Micheli', Laura Rogers-Bennett ${ }^{7,8}$, Carolina Olguin-Jacobson', Hugh P. Possingham ${ }^{1,10}$

${ }^{1}$ Centre for Biodiversity \& Conservation Science, School of Biological Sciences, University of Queensland, Brisbane, Queensland 4072, Australia. ${ }^{2}$ School of Earth and Environmental Sciences, University of Queensland, St. Lucia 4072, Australia. ${ }^{3} \mathrm{Global}-\mathrm{Change}$ Ecology Research Group, School of Science and Engineering, University of the Sunshine Coast, Maroochydore, QLD, Australia. ${ }^{4}$ Department of Zoology, Centre for African Conservation Ecology, Nelson Mandela University, Port Elizabeth, South Africa. ${ }^{5}$ Instituto de Investigaciones Oceanológicas, Universidad Autónoma de Baja California, Ensenada, Mexico. ${ }^{6}$ Hopkins Marine Station and Stanford Center for Ocean Solutions, Pacific Grove, CA 93950, USA. ${ }^{7}$ Karen C. Drayer Wildlife Health Center, University of California, Davis, Bodega Marine Laboratory, Bodega Bay, CA 94923, USA. ${ }^{8}$ California Department of Fish and Wildlife, Bodega Bay, CA 94923, USA. ${ }^{9}$ Australian Rivers Institute, School of Environment and Science, Griffith University, Southport, QLD 4215, Australia. ${ }^{10}$ The Nature Conservancy, Arlington, VA 22203-1606, USA *Corresponding author. Email: n.arafehdalmau@uq.net.au

REFERENCES AND NOTES

1. D. R. Schiel, M. S. Foster, The Biology and Ecology of Giant Kelp Forests (University of California Press, Oakland, CA, 2015).

2. T. L. Frölicher, E. M. Fischer, N. Gruber, Nature 560, 360 (2018).

3. D. A. Smale, New Phytologist 10.1111/nph.16107 (2019).

4. IPCC, "Summary for Policymakers," in IPCC Special Report on the Ocean and Cryosphere in a Changing Climate, H.-O. Pörtner et al., Eds. (2019).

5. K. C. Cavanaugh, D. C. Reed, T. W. Bell, M. C. Castorani, R. Beas-Luna, Front. Mar. Sci. 6, 413. (2019).

6. N., Arafeh-Dalmau et al., Front. Mar. Sci. 6, 499 (2019).

7. L. Rogers-Bennett, C. A. Catton, Sci. Rep. 9, 1 (2019).

8. “COP25 Climate change talks: 'We've lost an important opportunity,"' BBC (2019) www.bbc.com/news/science-environment50801493.

9. W. J., Sutherland et al., Trends Ecol. Evol. 34, 139 (2019).

10. D. P. Tittensor et al., Sci. Adv. 5, eaay9969 (2019)

11. P. Friedlingstein et al., Earth Syst. Sci. Data 11, 1783 (2019).

12. E. C. Oliver et al., Front. Mar. Sci. 6, 734 (2019).

10.1126/science.aba5244 